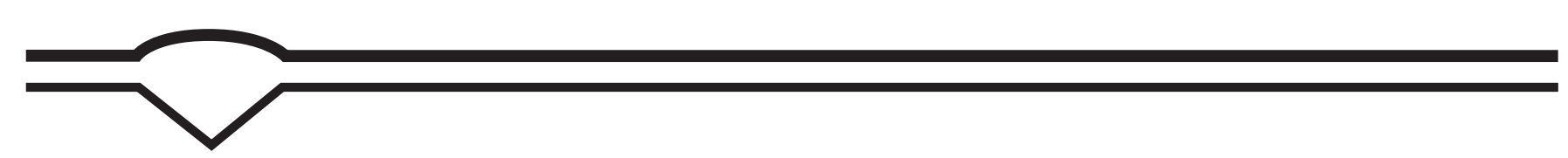

\title{
Use of a cell-based interactive wound dressing to enhance healing of excisional wounds in nude mice
}

\author{
RILEY S. REES, MD, FACSa; BELINDA F. ADAMSON, MEdb; WILLIAM J. LINDBLAD, PhDc
}

The need to have viable, metabolically active cells to heal wounds is well recognized, because there is clear evidence that cellular dysfunction delays healing. This suggests that addition of metabolically active cells to a delayed healing tissue could enhance the healing of the tissue. Therefore, we examined the ability of an interactive wound dressing composed of human keratinocytes or fibroblasts grown on microporous bio-reactor beads and placed into a polyethylene bag to facilitate the delayed healing of wounds in nude mice. A $1 \times 1 \mathrm{~cm}$ wound was made on the backs of nude mice, and the dressing with or without viable cells was placed on the wound for 8 to 24 days, with dressing changes every other day. Wound area and time to heal measurements were compared after various interventions including freeze-thawing. The data shows that the interactive wound dressing was more effective than the control dressings $(p<0.05)$ and that keratinocytes were more effective than fibroblasts in wound healing $(p<0.05)$. Freezingthawing of the interactive wound dressings destroyed the activity of the dressing. Studies examining cells using a live/ dead viability assay showed that both keratinocytes and fibroblasts were alive after 2 days on the mice. Surprisingly, human fibroblasts appeared to exhibit bridging behavior that is indicative of fibroblast proliferation. We conclude that a simple interactive wound dressing using either keratinocytes or fibroblasts can enhance the healing of wounds in nude mice. (WOUND REP REG 2001;9:297-304)

Healing of damaged tissue is an energy dependent process requiring multiple healthy cell types synthesizing and secreting numerous protein regulatory molecules. Recently, studies have suggested that failure to heal wounds may result from cellular dysfunction resulting in, among other factors, a lack of essential growth factors within the wound bed. ${ }^{1-3}$ The need for innovative therapies to treat this cellular dysfunction is a key component to the successful treatment of the 3 million diabetic foot

From the Section of Plastic Surgerya, Department of Surgery, University of Michigan Medical Center, and Research Branchb, Veterans Affairs Health Care System, Ann Arbor, Michigan; and Department of Pharmaceutical Sciences'; College of Pharmacy and Allied Health Professions, Wayne State University, Detroit, Michigan.

Reprint requests: Riley S. Rees, MD, FACS, Section of Plastic Surgery, University of Michigan Medical Center, 1500 East Medical Center Drive, 2130 Taubman Center, Ann Arbor, Ml 48109-0340. Fax: (734) 7635354; Email: rreese@umich.edu

Copyright (c) 2001 by The Wound Healing Society.

ISSN: 1067-1927\$15.00+0
IWD Interactive wound device

ulcers and one-half million pressure ulcers in the United States. Although several therapeutic approaches hold great promise, the application of healthy human cells to a non-healing wound is an attractive wound healing strategy.

The placement of human keratinocytes on various types of carrier dressings has been very successful. One study reported a 73\% success rate in healing 59 wounds treated with cultured sheets of keratinocytes. ${ }^{4}$ Phillips et al. ${ }^{5}$ also achieved a $73 \%$ success rate in skin ulcers using allogeneic epidermal sheets of keratinocytes derived from neonatal foreskin. Overall, 114 cases of successful use of allogeneic keratinocyte on wounds have been reported. ${ }^{4-9}$ This type of wound coverage using live cells has been defined by the United States Food and Drug Administration as an interactive wound dressing (IWD). ${ }^{10}$

Currently, the mechanism of action of the IWDs or 
skin substitutes is unclear. Studies by Achauer et al. ${ }^{11}$ have shown that keratinocytes will attach and proliferate in immunosuppressed burn patients. However, it is unclear if these events occur in immunocompetent hosts. Long-term studies of burn wounds transplanted with keratinocytes show that keratinocyte grafts do not produce the normal epidermal and dermal elements present in non-wounded skin. ${ }^{12}$

There is great clinical interest in the development of cell based wound therapies using a collagen matrix as a platform for cells. The skin substitute, Apligraf ${ }^{\circledR}$, composed of neonatal keratinocytes and fibroblasts, is commercially available for the treatment of venous stasis ulcers. ${ }^{13-15}$ Dermagraft ${ }^{\circledR}$, also a skin substitute, is composed of fibroblasts and a collagen matrix and is currently in the final stages of clinical trials to treat diabetic foot ulcers.

Pruitt and Levine ${ }^{16}$ suggested that the ideal wound dressing shows tissue compatibility, adherence to the wound surface, flexibility, elasticity, and protection against bacteria. These attributes contribute significantly to the wound healing effect. Skin substitutes and IWDs, in contrast to traditional dressings, have the added benefit of living cells. This component may significantly add to the wound healing potential, although evaluating the efficacy of IWD and skin substitutes may be complex given the variety of materials present in the device. These materials include a biological matrix, dressing materials, and a variety of living cells. Therefore, skin substitutes and IWDs provide many of the attributes of the ideal dressing. ${ }^{16}$

In this study, we tested the hypothesis that normal human allogeneic keratinocytes or fibroblasts grown on a platform of polyethylene coated silica microcarrier beads enclosed in fine mesh fabric are an effective IWD. Our results suggest a powerful wound healing effect by this type of IWD.

\section{MATERIALS AND METHODS}

All surgical procedures were performed under sterile conditions within a laminar flow hood located within a containment area where the nude mice were housed. Five-week-old female Nu/J mice (Jackson Labs, Bar Harbor, ME) were anesthetized with metofane (Mallinckrodt, Veterinary, St Louis, MO) and an area on the dorsum cleansed with ethanol. Using fine surgical scissors, a full thickness wound approximately $100 \mathrm{~mm}^{2}$ in area was created. The wound dressings were secured to the wound using surgical staples to the cephalad end, covered with a Band-Aid ${ }^{\top \mathbb{W}}$ (Johnson \& Johnson, New Brunswick, NJ) before the mice were returned to their biohazard contain- ment cages. Every other day the mice were returned to the laminar flow hood, lightly restrained while wound area and photographic measurements were obtained, and the dressing replaced and secured. The animal protocol was approved by the Institutional Animal Use Committee of the VA Ann Arbor Healthcare System.

\section{Preparation of human keratinocytes}

Human keratinocytes were obtained from breast skin removed during surgical procedures performed at the University of Michigan Hospital. Informed consent was obtained from all patients, and the University of Michigan Institutional Review Board approved this protocol. Skin was harvested in accordance with the guidelines of the American Association of Tissue Banks. The split thickness skin was placed, dermis side down, into $150 \mathrm{~mm}$ Petri dishes, cut into small pieces $(2 \mathrm{~cm} \mathrm{x} 0.3 \mathrm{~cm})$ and soaked in a sterile solution of $30 \mathrm{mM}$ HEPES, $10 \mathrm{mM}$ glucose, $3 \mathrm{mM} \mathrm{KCl}, 130 \mathrm{mM} \mathrm{NaCl}, 1 \mathrm{mM} \mathrm{Na}_{2} \mathrm{HPO}_{4}$ buffer, $\mathrm{pH} 7.4$ containing 50 units of penicillin and $50 \mu \mathrm{g}$ streptomycin (Sigma Chemical Co, St. Louis, MO). After soaking the tissue for 1-2 hours at $4^{\circ} \mathrm{C}$, the buffer was aspirated, and $0.09 \%$ trypsin (Sigma, Type IX) in the penicillin and streptomycin buffer was added to the dishes. Following overnight trypsinization at room temperature, the enzyme solution was removed and modified complete MCDB 153 medium (Sigma) containing trypsin soybean inhibitor was added to the skin pieces. The dermis was separated from the epidermis, and the epidermal basal keratinocytes were gently scraped from both segments of the skin. The cell suspension was pooled into $50 \mathrm{ml}$ conical centrifugation tubes, subjected to low speed centrifugation at room temperature, and re-suspended in 50 $\mathrm{ml}$ of complete medium plus $2 \%$ chelexed fetal bovine serum (Sigma). The keratinocytes were counted using a hemocytometer, and $20 \times 10^{6}$ keratinocytes were plated into T-75 Corning plastic flasks and grown at $37^{\circ} \mathrm{C}$ with $5 \% \mathrm{CO}_{2}$, in a humidified incubator.

Three days later, growth medium was removed and complete MCDB 153 without serum was added. The keratinocytes were re-fed every other day and passaged during the log phase of growth. The keratinocytes were trypsinized using 0.025\% trypsin (type IX, Sigma) plus $0.01 \%$ EDTA in HEPES buffer. The monolayers were washed with the buffer twice and then 2-3 $\mathrm{ml}$ freshly made enzyme solution (or frozen aliquot) was added. After 1 minute at $37^{\circ} \mathrm{C}$, the enzyme solution was gently suctioned off and the flasks held at $37^{\circ} \mathrm{C}$ for $2-3$ minutes, until the cell sheets came off with gentle tapping of the flask bottom. The media was neutralized with 1-3 $\mathrm{ml}$ of MCDB 153 medium plus 0.03\% trypsin soybean inhibitor (Sigma). The cells were counted, centrifuged and plated 
at $0.5-1.0 \times 10^{6}$ cells per T-75 flask. Cells were passaged 3 to 4 times.

\section{Processing of microcarrier beads}

Five grams of Cytoline 1 (Amersham, Piscataway, NJ) beads were autoclaved for 10 minutes in $40 \mathrm{ml}$ deionized water in a $125 \mathrm{ml}$ Erlenmeyer flask. The beads were cooled, the water aspirated, and $80 \mathrm{ml}$ of deionized water was added. The mixture was agitated at moderate speed on a Labline orbital shaker for 10 minutes. The water was removed, $80 \mathrm{ml}$ of deionized water added, and the washing process repeated two more times. The beads were transferred to a $250 \mathrm{ml}$ plastic tube, the water was removed and $40 \mathrm{ml} 0.1 \mathrm{~N} \mathrm{NaOH}$ was added. The beads were incubated at room temperature overnight, the $\mathrm{NaOH}$ solution was removed and the beads were resuspended in $50 \mathrm{ml}$ of deionized water. The aliquot was transferred to a 125 Erlenmeyer flask where the wash step was repeated five times until the final $\mathrm{pH}$ was $<8.0$. The water was aspirated and the beads were again suspended in $40 \mathrm{ml} \mathrm{PBS}$ minus $\mathrm{Mg}++$ and $\mathrm{Ca}++$, and autoclaved for 30 minutes at $121^{\circ} \mathrm{C}$.

\section{Keratinocyte cultures on microcarrier beads}

Prepared beads were suspended in MCDB 153 complete medium in a culture bottle and conditioned at $37^{\circ} \mathrm{C}$ with $5 \% \mathrm{CO}_{2}$ for 48 hours. The medium was aspirated and 10 to $15 \mathrm{ml}$ of medium was added. The medium was removed and $20 \times 10^{6}$ cells per $1 \mathrm{ml}$ of beads were added. This mixture was gently swirled once an hour for 3 hours, then incubated overnight. The cells and beads were decanted into a roller bottle and $50 \mathrm{ml}$ of medium was added. Five $\mathrm{ml}$ of cells and beads were removed from the glass roller bottle and grown in a T-25 flask to determine the growth of the cells on the plastic bottom of the flask in the presence of the beads. The roller bottle was incubated overnight at $37^{\circ} \mathrm{C}$, after which $100 \mathrm{ml}$ additional medium was added to the roller bottle and the rotation of the roller bottle was initiated. The rotation rate was one turn per 15 seconds. When the cells were re-fed every 48 hours, an aliquot of medium was removed and replaced by fresh medium.

\section{Preparation of fibroblast populated beads}

After separation of the dermis from the epidermis and the removal of most of the adhering cells, the dermal skin layer was put into collagenase/phosphate buffered saline solution (PBS, $50 \mathrm{mg}$ collagenase type XI, Life Technologies, New York). After gentle stirring at room temperature for one hour, the cells were filtered from the dermal suspension using a 240-micron mesh filter. The cells were centrifuged in a $50 \mathrm{ml}$ tube at $1000 \mathrm{rpm}$ at room temperature, $1-2 \times 10^{6}$ cells were placed into $15 \mathrm{ml}$ Dulbecco's Modified Eagle Medium (DMEM, Sigma) plus $10 \%$ fetal bovine serum (complete medium) and grown in a T-75 flask under $5 \% \mathrm{CO}_{2}$ at $37^{\circ} \mathrm{C}$. The primary cultures were passaged using $0.03 \%$ trypsin and $0.01 \%$ EDTA at a 1:3 split. Ten flasks of an adult human fibroblast cell strain were trypsinized, resulting in $38 \mathrm{X}$ $10^{6}$ cells in a volume of $10 \mathrm{ml}$ of DMEM complete medium. Processed Cytoline 1 beads were prepared for culture by removing the PBS and soaking the beads in twice the volume of complete medium for 48-72 hours. After the soaking medium was removed, $100 \mathrm{ml}$ of fresh complete medium was added.

Prior to plating the cells onto Cytoline 1 beads, the medium was removed from the beads and $10 \mathrm{ml}$ of fibroblast cell suspension was added to $20 \mathrm{ml}$ of the packed microcarrier beads, in a sterile $50 \mathrm{ml}$ centrifuge tube. The cells and beads were gently mixed and transferred to a $250 \mathrm{ml}$ sterile glass bottle and placed in a $5 \% \mathrm{CO}_{2}$ incubator at $37^{\circ} \mathrm{C}$. After one hour, $100 \mathrm{ml}$ additional complete medium was added and the cells and beads were incubated overnight. The top of the bottle allowed gassing of the cell/bead suspension. After 24 hours, the cell/ microcarrier bead suspension was transferred to a Kontes $250 \mathrm{ml}$ bio-reactor, and grown with gentle stirring under standard incubator conditions. One-fourth the medium volume of the fibroblast/bead suspension was refreshed every second day.

\section{Preparation of bead bags}

Microcarrier beads coated with cells were contained within a delnet (Applied Extrusion Technologies, Inc., Peabody, MA) bag approximately $23 \times 25 \mathrm{~mm}$ in size. Three seams were created in the pouch with an Impulse Heat Sealing Unit (American International Electric Co., Santa Fe Springs, CA), and then gas sterilized with ethylene oxide. The cell/bead suspension $(250 \mu \mathrm{l})$ was added to the delnet bag with a glass pipet. After the beads containing cells were loaded into the bag, the final seam was created with the Impulse Heat Sealing Unit, and the assembled bags were placed into tissue culture media until used. The bag and bead assembly was performed in a laminar flow tissue culture hood.

\section{Measurement of wound area}

Determination of the total wound area was performed as previously described. ${ }^{17}$ Briefly, the area of the wound was traced onto a transparent sheet (Labelon Corp, Canadaigua, NY) with a fine marker. The transparent sheet was photocopied and the copy was scanned using an HP ScanJet 4C (Hewlett-Packard Co, Boise, ID). Tissue area was calculated with a non-rectangular area analysis used by NIH image 1.44. The data was expressed as millimeters 
squared. Mean and standard deviation were calculated using Statworks (SPSS, Inc.).

\section{Histologic evaluation}

Excised wounds were placed into 10\% buffered formalin, processed in an IL MVP Tissue Processor (Instrumentation Laboratory, Lexington, MA), then embedded in paraffin utilizing the clinical histology section of the Ann Arbor VA Medical Center. The tissues were cut into 5 $\mu \mathrm{m}$ sections and stained using routine hematoxylin and eosin staining. Microscopic examination and photography of the slides were done on a Zeiss Axiophot photomicroscope (Carl Zeiss, Germany).

\section{Photography of beads}

Human keratinocytes that were grown on Cytoline $1 \mathrm{mi}-$ crocarrier beads were stained with Kreyberg stain. ${ }^{18}$ The cells and beads were fixed in $6 \%$ trichloroacetic acid for at least one hour before they were rinsed in $70 \%$ ethanol for five seconds and distilled water twice. Thereafter, they were stained with Mayer's Hematoxylin for $4 \mathrm{mi}-$ nutes and rinsed with running tap water for 3 minutes to stain the nuclei blue. The cells and beads were stained with $1 \%$ aqueous erythrosin for 3 minutes and rinsed with tap water for 10 seconds before rinsing with $80 \%$ ethanol and again with tap water. Thereafter, the microcarrier beads were suspended in tap water, and examined and photographed using a Nikon inverted microscope.

\section{Cell viability assay}

A two-color fluorescence dye assay (LIVE/DEAD ${ }^{\circledR}$ Viability Kit, Molecular Probes, OR) was used to examine the number of viable cells on the microcarrier beads after placement in the mice wounds. A working solution of $4 \mu \mathrm{M}$ ethidium homodimer- 1 and $2 \mu \mathrm{M}$ calcein $\mathrm{AM}$ in sterile phosphate buffered saline solution was added to the cell coated beads in a Petri dish. After a 20-minute incubation at $37^{\circ} \mathrm{C}$, the cell-coated beads were viewed under a fluorescence microscope.

\section{RESULTS}

We examined how keratinocytes interacted with silica/ polyethylene microcarrier beads contained within a polyethylene mesh bag. Figure 1 shows keratinocytes grown on microcarrier beads photographed on a tissue culture dish. Note the irregularity of the beads and high density of keratinocytes achieved on the microcarrier beads.

Initially, we tested the wound healing effectiveness of human keratinocytes used as an IWD on nude mice wounds. One $\mathrm{cm}^{2}$ wound was created on the back of each of twenty mice, and the wounds were dressed with either the IWD or mesh bag alone. All wounds were

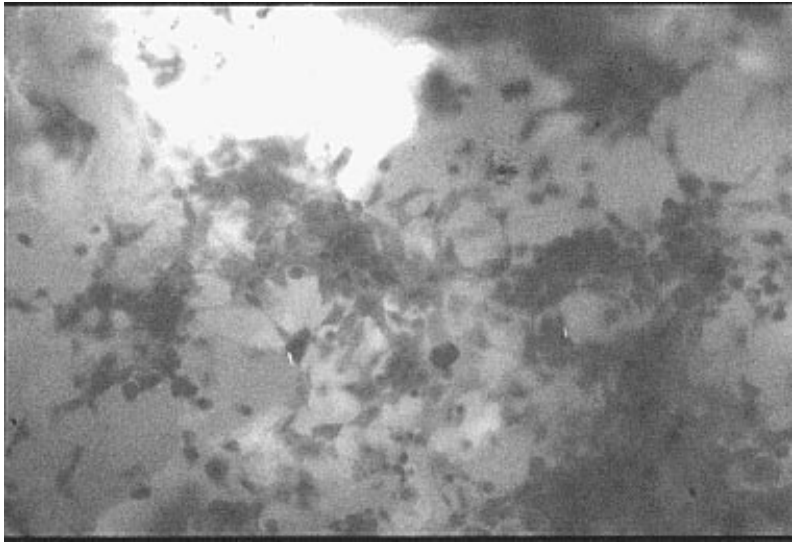

Figure 1. Photomicrograph showing human allogeneic keratinocytes grown on microcarrier beads. Note the confluence of the cells on the irregular surface of the beads. The photomicrograph was taken 5 days after the cells were inoculated.

covered with a Band-Aid ${ }^{\mathrm{Im}}$ as an overdressing, and the dressing replaced every other day for the 8-day duration of the experiment. Before each dressing change, the wounds were debrided and the area measured. The results of this pilot experiment are shown in Figure 2. The data indicate that wound size was reduced in both groups, but the reduction was greater at days 2,4 , and 8 in the IWD group $(\mathrm{p}<0.05)$. The wound healing effect was most pronounced at day $4(\mathrm{p}<0.008)$. These wounds had a confluent epidermis covering the wounded area

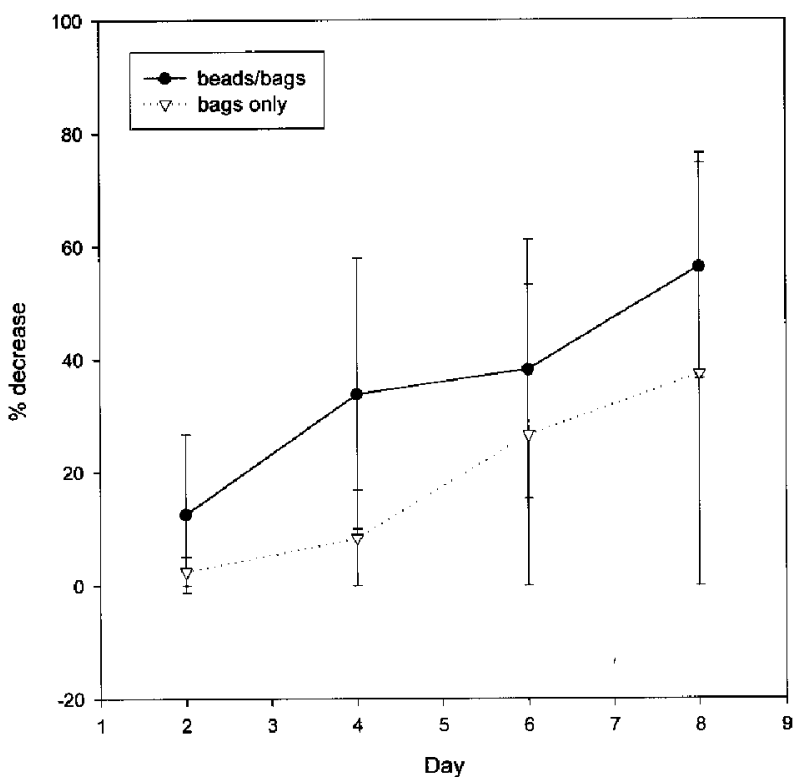

Figure 2. Reduction in wound area in a 10-day trial comparing the Delnet bag and the keratinocytes/beads in the bag. The mean \pm SD wound area for each group $(n=10)$ was plotted for each data point. 
after they were healed (Figure 3) and there was evidence that dermal components had regenerated.

We proposed that the wound healing effect was related to the contribution of living keratinocytes. Therefore, we snap froze the IWD before application to the wound. In this experiment, there were three groups of animals $(\mathrm{n}=8)$ with a control group treated with the Band-Aid $^{(\mathbb{I}}$ cover dressing only. The data in Figure 4

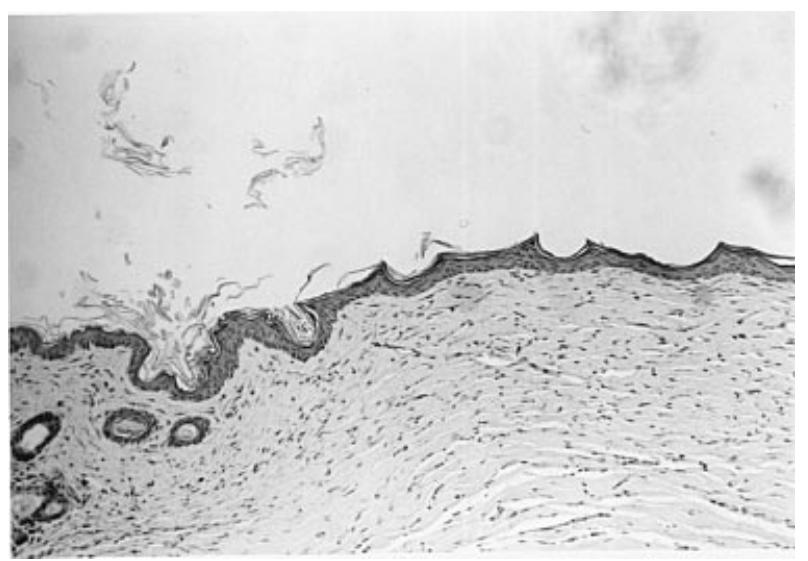

Figure 3. Histological evidence of wound healing in the nude mouse on day. Note the epidermal layer extends across the wound. There is evidence of regeneration of the dermis in these experiments.

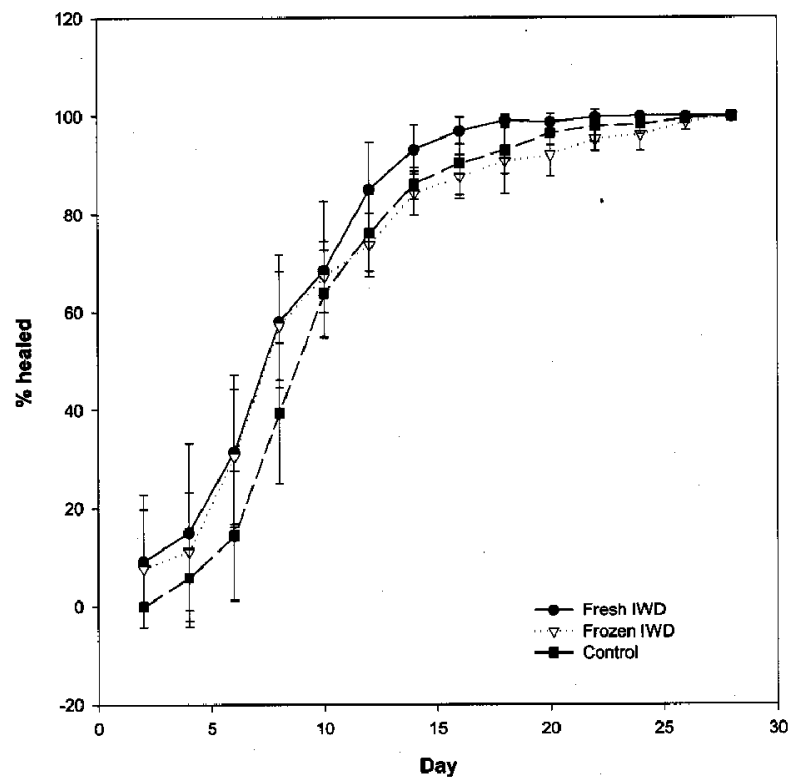

Figure 4. Results of a three-armed study comparing the IWD, frozen IWDs and the Band-Aid ${ }^{\text {(im }}$ dressing. In these experiments, IWDs showed a statistically significant reduction in wound area that was noted at day 10 ( $p<0.05$ ). IWDs and frozen IWDs appeared to have identical wound healing curves prior to that time. Both fresh and frozen cells performed better than control wounds ( $p<0.05$ ) until day 10. In the three groups, all wounds were healed by day 28 . Values represent mean $\pm S D$.

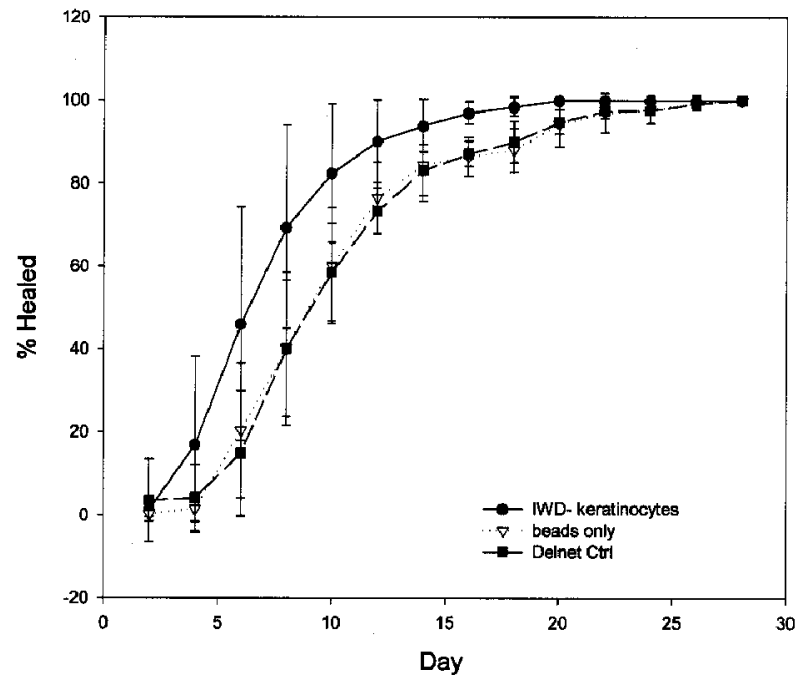

Figure 5. A three-armed study of wound healing comparing beads only in a Delnet bag, Delnet, and IWDs. The wounds were measured until they were healed. The data (mean \pm SD) shows a statistically significant reduction in wound area using IWDs starting at day $6(\mathrm{p}<0.05)$. All the wounds in the IWD group were healed by day 20 .

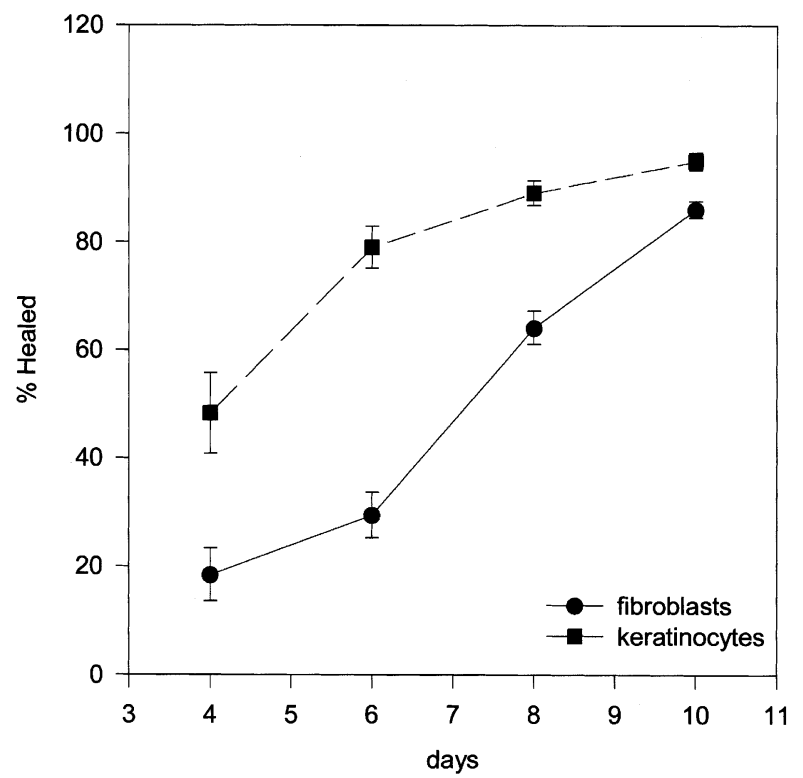

Figure 6. Wound healing potential of keratinocytes and fibroblasts on beads in a bag were compared over 10 days. The mean area $( \pm S D)$ was plotted between the two groups $(n=$ 10). Note that by day 4 , the keratinocyte preparation was substantially more active than the fibroblasts. The average number of beads in the fibroblast group was higher $(n=112)$ than in the keratinocyte bags $(n=80)$.

indicates there was no difference between frozen keratinocytes and fresh keratinocytes in the IWD until day $10(\mathrm{p}<0.05)$. Both fresh and frozen IWD performed 


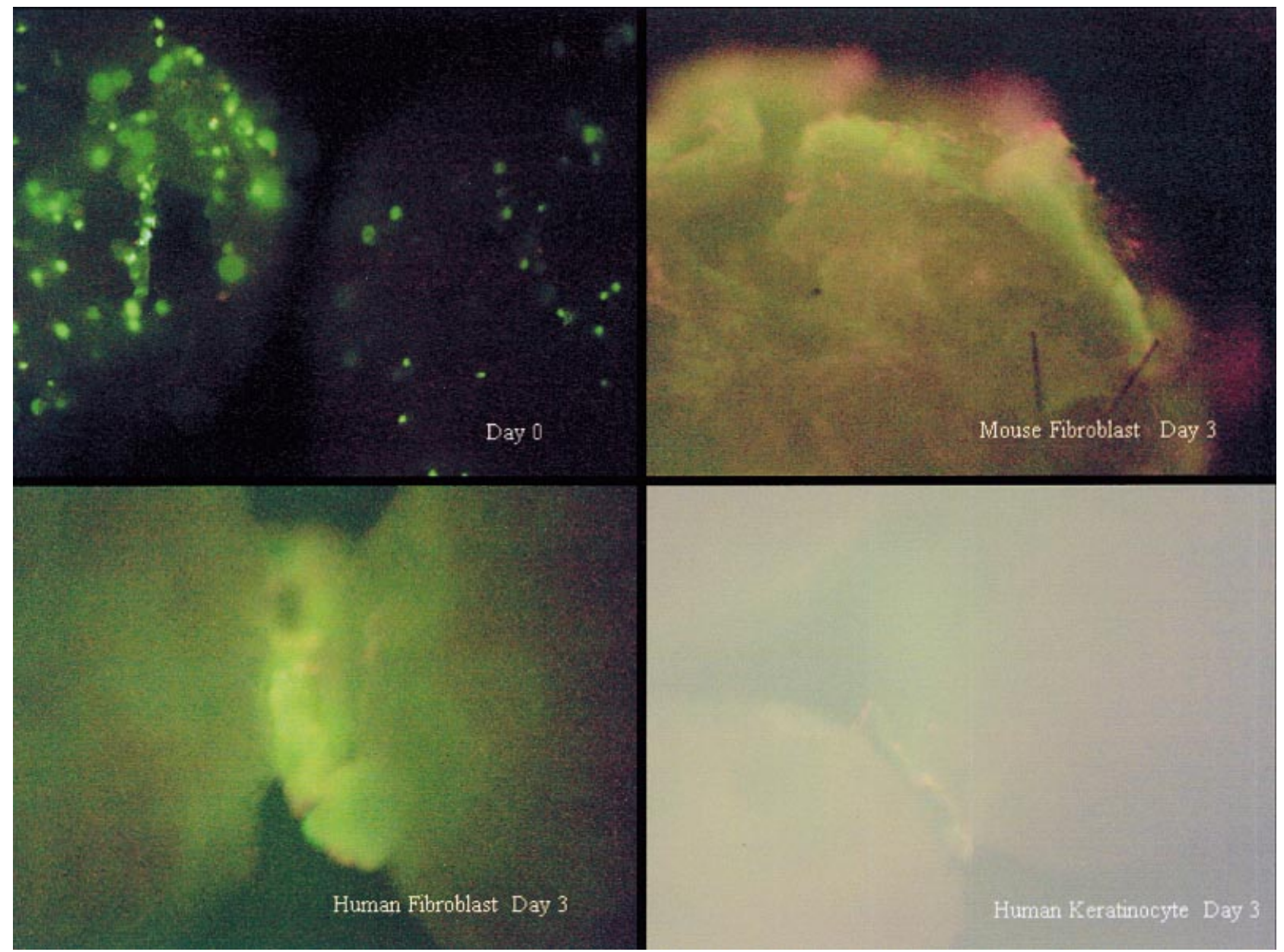

Figure 7. Photomicrograph showing the results of a live/dead cell assay. This figure compares human fibroblasts, human keratinocytes, and mouse fibroblasts at day 3 on mouse wounds. The upper left shows control human fibroblasts, lower left shows human fibroblasts, upper right shows mice fibroblasts, and the lower right shows human keratinocytes.

better than the control wounds $(\mathrm{p}<0.05)$. In the three groups, all wounds were healed by day 28 .

Because the IWD is assembled from several different components, e.g. Delnet bag, microcarrier beads, etc, we sought to determine the contribution of each component to the wound healing effect. Therefore, 8 mice in three groups treated with either Delnet bags, microcarrier beads in Delnet bag, or complete IWD, were studied for their vulnerary activity. The wounds were debrided, measured, and the dressings changed every other day. The data in Figure 5 shows statistically significant reduction in wound area in the mice treated with complete IWDs starting on day $6(p<0.05)$. This effect persisted throughout the experiment. Eighty percent of mouse wounds in the IWD group healed within 14 days.

These data all suggested that a wound healing effect was produced only when IWDs contained keratinocytes. Therefore, we tested the hypothesis that any cell would have wound healing properties by examining the effect of fibroblast populated microcarriers on wound healing in the mouse. Again, nude mice $(n=18)$ were equally divided into groups and treated either with keratinocyte populated wound devices or fibroblast coated beads. In a 10-day trial, the data as presented in Figure 6 show a highly significant difference in healing between keratinocytes and fibroblasts in the IWD $(\mathrm{p}<0.004)$. The reduction in wound area was greatest at day 6 . The data suggests that different cell types function differently inside the IWD.

In a final series of experiments, we determined the longevity of human or murine fibroblasts or human keratinocytes in the IWD after they were placed in the wound. Using a live/dead assay, IWDs were removed from the wound bed after they were in contact with the wounds for 1, 2, or 3 days. Figure 7 shows that human fibroblasts are alive at 3 days (lower left) with little evidence of dead cells. Note that the fibroblasts appear to be bridging between the beads. The mouse fibroblasts (upper right) 
show areas of orange staining, suggestive that some cells are dying. However, the mouse fibroblasts were alive at days 1 and 2 (data not shown). The keratinocytes appear to have some cells that are alive, although there is evidence of dying cells at 3 days.

\section{DISCUSSION}

These experiments suggest that IWDs have the potential to enhance the wound healing capacity of nude mice. The platform design uses beads in a fine mesh bag and differs greatly from the collagen and polyglycolic acid matrices used in skin substitutes. ${ }^{12}$ Although all the devices allow anchorage dependent cell growth and proliferation, our versatile bead platform can be adapted to almost any cell type. The less cumbersome design makes the system more versatile to manufacture and apply to wounds.

There are key attributes that distinguish the IWD from skin substitutes. Our experiments in the mouse wound show that repeated applications are possible because the IWD functions as a dressing and can be removed from the wound. Therefore, fresh cells can be frequently replaced if the wound is contaminated. Our experiments also show that different cell types behave differently in the mouse wounds. In the nude mouse, human keratinocytes were the most effective in promoting wound healing because these cells promoted reepithelialization. Fibroblasts may be more effective in wounds that require collagen production, such as a dehisced surgical wound.

The mechanism of action of these IWDs in the nude mouse models is speculative. It is likely that keratinocytes in the IWD secrete paracrine factors that regulate fibroblast collagen production. The charge beads may also have wound healing properties that activate local cells. This wound healing effect may simply be additive with the absorptive properties and debriding qualities of the IWD which should be similar to traditional dressings. ${ }^{16}$

Unfortunately, the mechanism of wound closure in the mouse models differs from human chronic wounds where pressure ulcers and diabetic foot ulcers heal through wound contraction. ${ }^{1,3}$ In the nude mouse, reepithelialization plays a prominent role in wound healing. Because previous clinical data from other keratinocyte preparations were reported to be effective in wound repair, our pre-clinical data using the IWD strongly suggest it will be effective in human wounds. Clearly, they may provide the ideal protective dressing, or possibly be enhanced to deliver a variety of growth factors, which have been previously shown to improve healing. ${ }^{19,20} \mathrm{We}$ recog- nize that these predictions may not be sustainable in human wounds. Only clinical trials will provide the answer.

\section{ACKNOWLEDGMENTS}

These studies were supported by the Office of Research and Development, Medical Research Services, Department of Veterans Affairs. We thank Cynthia Marcelo, PhD and Bob Gilmont, PhD for contributing to intellectual support for the manuscript.

\section{REFERENCES}

1. Steed DL. Clinical evaluation of recombinant human platelet-derived growth factor for the treatment of lower extremity diabetic ulcers. Diabetic Ulcer Study Group. J Vasc Surg 1995;21:71-8.

2. Wieman TJ, Smiell J, Su Y. Efficacy and safety of a topical gel formulation of recombinant human platelet derived growth factorBB (becaplermin) in patients with chronic neuopathic diabetic ulcers. A phase III randomized placebo-controlled double-blind study. Diabetes Care 1998;21:822-7.

3. Rees RS, Robson M, Smiell J, Perry B, and the Pressure Ulcer Study Group. Becaplermin gel in the treatment of pressure ulcers: a phase II randominzed, double-blind, placebo-controlled study. Wound Rep Reg 1999;7:141-7.

4. Leigh IM, Purkis P, Nasaria H, Phillips TJ. Treatment of chromic venous ulcers with sheets of cultured allogenic keratinocytes. $\mathrm{Br}$ J Dermatol 1987;117:591-7.

5. Phillips TJ, Kehinde O, Green H, Gilchrest BA. Treatment of skin ulcers with cultured epidermal allografts. J Am Acad Dermatol 1989;21(2 Pt 1):191-9.

6. Faure M, Mauduit G, Schmitt D, Kanitakis J, Demidem A, Thivolet J. Growth and differentiation of human epidermal cultures used as auto- and allografts in humans. Br J Dermatol 1987;116:161-70.

7. Brysk MM, Raimer SS, Pupo R, Bell T, Rajaraman S. Grafting of leg ulcers with undifferentiated keratinocytes. J Am Acad Dermatol 1991;25(2 Pt 1):238-44.

8. Hefton JM, Caldwell D, Biozes DG, Balin AK, Carter DM. Grafting of skin ulcers with cultured autologous epidermal cells. J Am Acad Dermatol 1986;14:399-405.

9. Cony M, Donatien PH, Beylot C, Géniaux M, Maleville J, Bzian JH, Taíeb A. Treatment of leg ulcers with an allogeneic cultured keratinocyte-collagen dressing. Clin Exp Dermatol 1990;15:410-4.

10. FDA General and Plastic Surgery Devices Advisory Panel. Draft guidance for the preparation of an IDE submission for an interactive wound and burn dressing. 1995.

11. Achauer B, Hewitt C, Black K, Martinez S, Waxman K, Ott R, Furnas D. Long-term skin allograft survival after short-term cyclosporin treatment in a patient with massive burns. Lancet 1986;1(8471):14-5.

12. Sabolinski ML, Alvarez O, Auletta M, Parenteau NL. Cultured skin as a 'smart material' for healing wounds: experience in venous ulcers. Biomaterials 1996;17:311-20.

13. Wilkin LM, Watson S, Prosky SJ, Meunier S, Parenteua NL. Development of a bilayered living skin construct for clinical applications. Biotechnol Bioeng 1994;43:747.

14. Hansbrough JF, Morgan J, Greenleaf G, Parikh M, Nolte C, Wilkin L. Evaluation of Graftskin* composite grafts on full-thickness wounds on athymic mice. J Burn Care Rehabil 1994;15:346-53.

15. Smith DJ Jr. Use of Biobrane in wound management. J Burn Care Rehabil 1995;16:317-20. 
16. Pruitt BA Jr, Levine NS. Characteristics and uses of biologic dressings as skin substitues. Arch Surg 1984;119:312-22.

17. Schwarz DA, Lindblad WJ, Rees RS. Altered collagen metabolism and delayed healing in a novel model of ischemic wounds. Wound Rep Reg 1995;3:204-12.

18. Kreyberg histological lung carcinoma types: a morphological and biological correlation. Acta Pathol Microbiol Scand Supple 1962; 157.
19. Brown GL, Nanney LB, Griffen J, Cramer AB, Yancey JM, Curtsinger LJ 3rd, Holtzin L, Schultz GS, Jurkiewicz MJ, Lynch JB. Enhancement of wound healing by topical treatment with epidermal growth factor. N Engl J Med 1990;321:76-9.

20. Robson MC, Mustoe TA, Hunt TK. The future of recombinant growth factors in wound healing. Am J Surg 1998;176(2A Suppl): 80S-82S. 